\title{
Research on the Situation and Problems of the Neo- generation Migrant Workers' Pension Insurance Participation
}

\author{
Zhang Junxia (a post-graduate student) \\ Institute of Political Science and Law, \\ University of Jinan \\ Jinan, Shandong province, China
}

250022

\author{
Li Zonghua* (a professor) \\ Institute of Political Science and Law, \\ University of Jinan \\ Jinan, Shandong province, China \\ 250022
}

\begin{abstract}
Along with our country's social and economic cons truction, the new generation of migrant workers has become an indispensable backbone. In order to reduce the risk of old age migrant workers and reduce their worries, we need to implement resolutely the policy of their pension insurance. However, there are still many contradictory issues in China's new generation of migrant workers' pension insurance such as low participation rate, high rate of surrender, contradiction between low-income and high payment of pension insurance, high liquidity and transfer continuity. The contradiction between the neogeneration workers' own rights and company's interests. The reason comes from migrants own, company, and government. The measures to solve the problem of the migrant workers' pension insurance include reducing the insurance base appropriately, promoting the continuity of pension insurance, increasing the supervision and guidance of employers.
\end{abstract}

Keywords-New Generation of Migrant Workers; Pension Insurance; Insured Condition; Analysis of Root Cause

\section{ISSUE}

In the past 30-odd years of reform and opening, China's economy has acquired rapid development, meanwhile ,more and more migrant workers have entered the city, which has played a huge role in promoting the process of urbanization in China. Statistically, the number of migrant workers in China reached 269 million in 2014. Among them, the new generation of migrant workers accounted for $70 \%$ of the total number of migrant workers in cities and played an important role in the migrant workers group [1]. The term "new generation of peasant workers" was first proposed by Wang Chunguang, who is a researcher at the Institute of Sociology of the Chinese Academy of Social Sciences, and the project of "Study on the Social Institutional Environment of Urban Social Migration" was hosted by the Chinese Academy of Social Sciences in 2000. The phenomenon of migrant workers (including the new generation of migrant workers) has quickly become a heated issue of research and attention in academic circles, theoretical circles, and all works of life. While migrant workers promote economic development of our country, their own social rights and interests have not been well protected, especially for the pension insurance of the majority of migrant workers.
It is very important to solve the problem of pension insurance for the new generation of migrant workers. This issue has caused widespread concerns among scholars. $\mathrm{Li}$ Yingsheng believes that the dual urban and rural system of our country cannot be broken at once. Therefore, a transitional policy should be established to solve the problem of pension insurance for migrant workers [2]. Gui Shixun proposed that a transitional pension insurance system from rural areas to urban areas should be established, and the basic level of payment should be used to determine the standard of enjoyment of pension insurance [3]. Cai Haiqing believes that a national unified social security network platform should be established, and everyone has their own fixed personal accounts, thereby reducing the difficulty of cross-regional transfer of pension insurance [4]. Chen Yi believes that the wage level of migrant workers should be raised above the minimum wage standard, and that migrant workers should be included in the urban pension system [5]. In summary, the research on rural migrant workers has attracted the attention of the academic community, but most of them staying at the perspective of economic analysis. This article discusses problems existing in the implementation of the current pension insurance system from the perspective of sociology. And it has great significance to propose solutions for self-employment characteristics combined with the new generation of migrant workers.

\section{THE STATUS QUO OF THE NEW GENERATION OF MIGRANT WORKERS PENSION INSURANCE}

\section{A. Insured situation of new generation of migrant workers}

With the continuous understanding on pension insurance of the new generation of migrant workers, the proportion of people participating in pension insurance is gradually increasing, but the migrant workers participating in insurance only accounts for a small part of the majority of migrant workers. Although there is a growing trend, the proportion is small and the rate of participation is not high. On February 20th, 2011, the All-China Federation of Trade Unions issued a report on the "Investigation of New Generation of Migrant Workers in 2010 and Countermeasures and Suggestions.” Among the 1000 companies been surveyed, the rate of participation in the new generation of migrant workers' 
pension insurance was $67.7 \%$, which was 23.7 percentage points lower than that of urban employees [6]. There are more data on the participation rate of the new generation of migrant workers in the country. In 2011, the National Bureau of Statistics issued the "Quantity, Structure, and Characteristics of the New Generation of Migrant Workers.” The data shows that, overall, the proportion of new generation of migrant workers in China participating in social pension insurance is relatively low, and only $7.6 \%$ of companies, or employers pay pension insurance for new generations of migrant workers. They prefer to pay work-related injury insurance for new generations of migrant workers, less for medical insurance [7].

\section{B. Surrender situation of the new generation of migrant workers}

The current insured rate is very low, but the surrender rate is rising year by year. In recent years, the migrant workers in the Pearl River Delta, the Yangtze River Delta and other aggregating areas have continued to withdraw their insurance. In some areas, there are even more people who handle surrendering than those who apply for insurance which goes against the original principle of building an old-age insurance system. In 2007, a total of 4.939 million people took part in pension insurance in Shenzhen, but the number of surrenders at the end of the year reached 830,000 , and only 9,600 people successfully transferred pension insurance. According to a survey conducted by the Ministry of Human Resources and Social Security, the overall social pension participation rate of migrant workers in China is only $15 \%$, and the rate of surrender is as high as $40 \%[8]$. The employment of migrant workers has high liquidity, especially for the new generation of migrant workers. For them, the priority is the maximization of utility in the short term. In order to seek preferable employment opportunities, they often choose to continue job hopping and change jobs. This has greatly affected the continuity of migrant workers' participation. In addition, the issue of transference and continuation has not been effectively resolved. New generation migrant workers often choose to withdraw their funds, resulting in a low density of payment, and it is difficult to obtain substantial protection for pension benefits after retirement.

\section{ANAlysis of the RoOt Cause of the New- GENERATION MigRANT WORKERS' PENSION INSURANCE}

\section{A. The contradiction between the low-income of the new generation of migrant workers and the high payment of pension insurance}

The income level of the new generation of migrant workers is not attractable, while the level of daily life consumption is relatively high. The existing basic pension insurance policies in each region set the basis for payment and the proportion of contributions in accordance with the living standards of urban residents in different regions. It is difficult for the new generation of migrant workers to bear the economic ability and living standards at this stage. Taking the "Interim Measures for Endowment Insurance for Peasant Workers in Beijing" as an example, the monthly minimum wage standard for migrant workers in Beijing for the previous year is the base fee, and the old-age insurance premium is paid at the rate of $8 \%$. The monthly minimum wage in Beijing is 1,560 yuan. Calculated at an $8 \%$ rate, migrant workers are required to pay 124.8 yuan per person per month. This is clearly not a case for migrant workers whose jobs are unstable and whose average monthly income is only 1747.87 yuan. Small economic burden. Unreasonable payment bases and payment ratios set a high threshold virtually, which greatly reduced the enthusiasm of the new generation of migrant workers in participating in the insurance, and has a great impact on their confidence in longterm survival in the city. The lack of personal funds to pay for insurance becomes the primary reason for restricting their participation. China's current urban employee pension insurance has a higher payment standard, in which the employer pays $20 \%$ of the total salary and the individual pays $8 \%$ of the wage and the actual income level of the new generation of migrant workers in some industries is not optimistic, and some private enterprises have even passed the responsibility for the full payment of pension insurance for urban enterprise employees to migrant workers. Even if the minimum fee base is adopted as the standard, neo-generation migrants would bear a higher personal rate without governmental or corporation's subsidies, which raises the threshold for the new generation of migrant workers to participate in the urban employee pension insurance on the contrary, reduces the enthusiasm of the new generation of migrant workers in the insurance.

\section{B. Contradiction between the problem of high mobility and transfer continuity of the new generation of migrant workers}

The new generation of migrant workers possesses current mobility, and the frequency of changing jobs is higher. At present, there are many institutional obstacles in the transfer of China's social pension insurance. Although China has promulgated the method of transferring and continual relationship of the pension insurance, most of the provincial and municipal pension insurance revenues and expenditures are still dominated by county-level co-ordination and local administrations have promulgated corresponding policy regulations according to the actual situation. The provincial human-resource departments also faced the problems of decentralized and fragmented policies, adding to the difficulty of national fund pooling. Such institutional obstacles have adversely affected the transfer of insurance relations when the new generation of migrant workers move into employment, and have increased the cost of check-in. In addition, in accordance with national regulations, if the new generation of migrant workers move across provinces and get employment, only the individual account portion of the basic old-age insurance gets transferred, but the social coordinating portion remains in the original place, which may result in the loss of welfare during the transferring process. To reduce the enthusiasm of the areas with low contribution rates of the unified funds, when the new generation of migrant workers' pensions is transferred and relocated, the places where the rates are relatively low need to transfer the allowances to the places where the rates are higher. If the social security agencies cannot respond in a timely manner, and the new generation of 
migrant workers chooses to withdraw their insurance directly, they can only withdraw personal account funds and their social security rights cannot be guaranteed.

\section{The contradiction between the interests of the enterprises and rights of the new generation of migrant workers}

Enterprises are also involved in the pension insurance for migrant workers and one of the main contributions. However, unlike migrant workers, companies take their own business interests first, which determines their passive attributions in the migrant workers' pension insurance issues. It is precisely because companies are reluctant to pay pension insurance premiums for migrant workers. In the process of formulating policies, the government should hear the voice of the enterprise. The government should take measures to eliminate doubts and create opportunities for soliciting opinions. It is estimated that a balance will be struck between the benefits and costs of migrant workers' pension insurance adding to the enterprise. Only by facing their own social responsibilities, the company can eliminate the resistance to endowment insurance and fully understand that employees' participation in endowment insurance is not a harmful event. Enterprises actively participate in the related issues of migrant workers pension insurance and become active and fully express their will. We must give our own reasonable advice on the proportion of pension insurance contributions, payment methods, fund operations, and punishment measures, so as to truly safeguard the interests of the enterprise itself and migrant workers.

\section{THE STRATEGY OF PROMOTING THE NEW GENERATION} OF MIGRANT WORKERS TO ACTIVELY INSURED

\section{A. Appropriately reduce the base fee}

At present, China's urban pension insurance does not take into account the actual wage level of the migrant workers' groups and does not take into account the actual payment level of the contributions, and thus exceeds the migrant workers' own endurance. As a result, the migrant workers' collective enthusiasm for participation is inhibited. Due to the low wages of migrant workers, there is no capital that can be used to maintain basic living after participating in the insurance. Therefore, in this situation, the payment base should be appropriately reduced, and the threshold of migrant workers participating in insurance should be reduced, thereby increasing the enthusiasm of participation in the insurance. Second, we must establish a flexible payment method. Employees in cities and towns pay insurance premiums directly from the wages paid by their employers. However, migrant workers are more mobile and their sources of income are relatively unstable. For example, peasant workers in the construction industry calculate their wages during basic construction period. It is not until the end of the project that the project money can be obtained. There are special circumstances where wages cannot be paid in time and the normal wages of migrant workers are owed. The length of arrears is also mostly different. Someone who has a problem can only get paid after one or two years. As a result, migrant workers cannot pay insurance fees in time.

\section{B. Promoting the transfer continuity of pension insurance for the new generation of migrant workers}

Promoting the transfer continuity of the pension insurance relationship requires the country proceed from the macro perspective, adopt laws and regulations, and supervise all parties to assume the responsibilities of the new generation of migrant workers to participate in pension insurance, balancing the pattern of interests of the exporting and importing regions. For regions that have carried out innovations in the pension insurance system for migrant workers, they must promptly suspend and gradually embrace the original local migrant worker pension insurance system into the national unified pension insurance system. In specific operations, they can learn from the experience of advanced regions. At the same time, initiating pilot projects in some regions, and compensating for the loss of rights and interests of new generations of migrant workers or related third parties that may occur in the process of convergence and conversion, should be coordinated and supplemented by financial arrangements at all levels. In addition, in order to reduce or even avoid the risk of welfare loss in the process of transfer and to reduce the barriers of new generations of peasant workers participating in insurance, we can draw lessons from the advanced experience of EU countries, quantify social insurance rights, convert them according to rules, and adopt a subsection calculation. The way to determine social insurance benefits.

\section{Strengthening supervision and guidance of employers}

The principle of territorial possession of social insurance determines that the local government should bear the corresponding responsibility for the participation of new generations of migrant workers in social pension insurance, and the enterprises should clearly define the main identity of the new generation of migrant workers in the insurance. As for the employment behavior of enterprises, the government must do a good job of supervision and inspection to identify problems in a timely manner. For the occurrence of nonstandard employment practices that do not pay social pension insurance fees for new generations of migrant workers, they must make corrections, increase penalties, increase the unit's illegal costs, avoid the continuation and expansion of adverse effects, and effectively protect the new generation of migrant workers. To standardize the employment behavior of employers, we must also do a good job of propaganda work for social pension insurance.

For employers, the participation of old-age migrant workers in endowment insurance is a due obligation under our laws. The reality is that some employers have weak awareness of social insurance laws, especially private owners and individuals. Therefore, it is possible to educate and promote the social insurance laws and regulations for the legal persons of units and social security agencies, and urge them to take up the responsibility of participating in insurance for the new generation of migrant workers and fulfill their statutory obligations. In addition, companies are encouraged to consider empathy during the training, look at pension insurance from multiple angles, and explore the economic value of good operation for employers to "retain people" and "employment" for employers. Enterprises should raise the minimum wage 
level for new generations of migrant workers. Labor time and intensity should strictly abide by the relevant rules and regulations in China's labor laws. It is forbidden to deduct wages for new generations of migrant workers and adhere to the principle of equality and fairness so that they can enjoy the same wages as urban employees, treatment and benefits.

\section{CONCLUSION}

The new generation of migrant workers is a special group formed in the process of coordinating the dual urban-rural economic structure, and has made great contributions to building a well-off society in China. Therefore, the government should make greater efforts to give suggestions and solutions to the new generation of migrant workers in the social security system, and especially pay special attention to the implementation of the new generation of migrant workers pension insurance system. Since the new generation of migrant workers has a higher sense of belonging to towns than rural areas, the settlement of their pension insurance issues not only concerns the rights and interests of migrant workers themselves, but also relates to the stability of the country and the harmony of society. Therefore, improving the new generation of migrant workers pension insurance is an important way to realize people-oriented and build a harmonious society. As long as the national government and citizens work together, the problems in the implementation of the new generation of migrant workers' pension insurance system will eventually be resolved.

\section{REFERENCES}

[1] Wu Xiaohui. Current status of new generation migrant workers pension insurance [D]. Gansu Agricultural University, 2015.

[2] Xie Shuping, Yue Yue. Current situation and countermeasures of the new generation of migrant workers pension insurance [J]. Business Economics, 2016(10):10-13.

[3] Gui Shixun. Exploration and Suggestions on Endowment Insurance of "Migrant Workers" in Chinese Cities[J]. Journal of East China Normal University, 2009(5):12-17

[4] Cai Haiq ing. Institutional bottleneck and policy thinking of rural mig rant workers participating in endowment insurance [J]. Journal of Beijing Municipal Institute of Planned Labour Management, 2005(04):11-12.

[5] Chen Yi. Principles and ideas for solving the problem of old-age insurance for migrant workers[J]. Xue Hai, 2006 (5)

[6] Lv Guoquan. Investigation on the Situation of New Generation Migrant Workers in 2010 and Countermeasures[N]. Workers' Daily,2011-0221(001).

[7] The data is derived from the "Number, Structure and Characteristics of New Generation Migrant Workers” issued by the National Bureau of Statistics in March 2011.

[8] Yang Yang. An analysis of the institutional barriers of the new generation of peasant laborers' city integration: taking the endowment insurance system as an example[J]. Modern Business, 2015(12): 272273 